\title{
Biotechnological Potential of Streptomyces Siderophores as New Antibiotics
}

\author{
Luciana Terra ${ }^{\mathrm{a}}$, Paul Dyson ${ }^{\mathrm{b}}$, Norman Ratcliffe ${ }^{\mathrm{a}, \mathrm{b}}$, Helena Carla Castro ${ }^{\mathrm{a}}$, Ana Carolina Paulo \\ Vicente $^{\mathrm{c}^{*}}$
}

${ }^{a}$ Programa de Pós-Graduação em Ciências e Biotecnologia, IB, UFF, Brasil; 'binstitute of Life Science, Medical School, Swansea University, Singleton Park, Swansea,UK.; ${ }^{C}$ Laboratório de Genética Molecular de Microorganismos, Instituto Oswaldo Cruz, Rio de Janeiro, RJ, Brasil.

\begin{abstract}
BACKGROUND: Siderophores are small molecule iron-chelators produced by microorganisms and plants growing mostly under low iron conditions. Siderophores allow iron capture and transport through cell membranes into the cytoplasm, where iron is released for use in biological processes. These bacterial iron uptake systems can be used for antibiotic conjugation or as targets for killing pathogenic bacteria. Siderophores have been explored recently because of their potential applications in environmental and therapeutic research. They are present in Streptomyces, Gram-positive bacteria that are an important source for discovering new siderophores. OBJECTIVE: This review summarizes siderophore molecules produced by the genus Streptomyces emphasizing their potential as biotechnological producers and also illustrating genomic tools for discovering siderophores useful for treating bacterial infections. METHODS: The literature search was performed using PUBMED and MEDLINE databases with keywords siderophore, secondary metabolites, Trojan horse strategy, sideromycin and Streptomyces. The literature research focused on bibliographic databases including all siderophores identified in the genus Streptomyces. In addition, reference genomes of Streptomyces from GenBank were used to identify siderophore biosynthetic gene clusters by using the antiSMASH platform. RESULTS: This review has highlighted some of the many siderophore molecules produced by Streptomyces, illustrating the diversity of their chemical structures and wide spectrum of bioactivities against pathogenic bacteria. Furthermore, the possibility of using siderophores conjugated with antibiotics could be an alternative to overcome bacterial resistance to drugs and could improve their therapeutic efficacy. CONCLUSION: This review confirms the importance of Streptomyces as a rich source of siderophores, and underlines their potential as antibacterial agents.
\end{abstract}

Running Title: Streptomyces siderophores

Keywords: siderophores; Streptomyces; actinomycetes; sideromycin; bacterial infection; Trojan horse approach.

\section{INTRODUCTION}

Streptomyces spp are Gram-positive bacteria with high genomic guanine + cytosine content and are members of the phylum Actinobacteria [1]. These bacteria are widely distributed in environments (e.g. marine, plants, insect and soil) and characterized by hyphae, mycelial development and sporulation during their life cycle $[1,2]$.

Streptomycetes are currently known for the production of many secondary metabolites that have a crucial role for their survival in the soil and for the establishment of symbiotic associations with other organisms. These bioactive compounds also act as signaling molecules and function to eliminate competitors [3].

The production of metabolites by these microorganisms is of great commercial interest due to their diverse applications in industries, e.g. pharmaceutical, textile, food and agricultural. They are important sources of bioactive molecules, including antibiotics, antifungal, antitumor and immunosuppressive compounds [4].

Antimicrobial resistance has had dramatic impacts on public health systems due to the increased morbidity, mortality and costs of treating infectious diseases [5-8]. Furthermore, a failed therapy caused by resistant microorganisms is a burden to public health hospitals, leading to new consultations, diagnostic examinations, prescriptions, and hospital bed occupancy, thereby increasing costs $[9,10]$.

There is an increasingly long list of microorganisms that are multidrug-resistant to different chemical classes, and no longer susceptible to most of the available antimicrobial agents. Multiple resistance mechanisms exist among Grampositive and Gram-negative species with clinical and high 
economic impacts around the world [11-14]. Thus, there is a continuous and growing need for the discovery of new antimicrobial drugs $[15,16]$.

The development of new antibiotic delivery methodologies, involving, for example, siderophores, represents an alternative for fighting the antibiotic resistance crises. These methodologies provide an opportunity to recycle old antibiotics not used in clinical practices due to toxicity or resistance problems and have an immense potential for the delivery of antibiotics into bacterial cells due to their biological mechanisms [17-20].

The siderophores are compounds widely distributed in microbial species including among aerobic and facultative anaerobic bacteria and fungi, in which they function in the sequestration and transport of iron [21, 22]. Apart from their ecological importance, there is a great biotechnology potential of these molecules as biocontrol, biosensor, and bioremediation agents as well as use in innovative strategies for targeting pathogenic bacteria [23, 24].

This review that includes references since 1947 focuses on the potential of the genus Streptomyces as a biological source of siderophores with promising biotechnology applications, especially for targeting pathogenic bacteria. It also summarizes the importance of discovering new antibiotics exploring natural sources, Streptomyces, sideromycins, and siderophore-drug conjugates. Finally, it discusses the use of genomic approaches for identifying new siderophores in Streptomyces.

\section{SIDEROPHORES: \\ DEFINITION \\ AND IMPORTANCE}

Siderophores are organic compounds produced by some bacteria, fungi and plants that grow under low iron conditions. They play important roles once the bioavailability of iron in aerobic environments is scarce [25]. In order to acquire iron under these conditions bacteria employ, for example, a number of transport mechanisms, such as, siderophore-mediated iron assimilation systems with high binding affinity for iron [26].

Iron is an important environmental factor for the growth of plants, microbial organisms and animals [27]. Iron occurs as ferrous $\left(\mathrm{Fe}^{+2}\right)$ or ferric $\left(\mathrm{Fe}^{+3}\right)$ forms and the conversion between these two oxidation states is involved in important biological processes such as ATP biosynthesis, oxygen metabolism, DNA and RNA syntheses and biofilm formation $[24,28]$. Basically, siderophores solubilize the ferric iron from different terrestrial and aquatic habitats and thereby make it available for microbial and plant cells [29].

There is a constant battle between invading pathogenic bacteria and the host for iron with the host limiting iron availability and the bacteria secreting siderophores to sequester the iron. The host secretes lipocalins to interfere with siderophore iron acquisition but the bacteria produce stealth siderophores as a counter move and this leads to neutralization of the reactive oxygen system and myeloperoxidase inhibition and an impaired host response. The resistant bacteria then multiply and the changes to the microbiota can lead to acute inflammatory insults and diseases like inflammatory bowel disease and colorectal cancer [18-19].

Iron can also be toxic as it is related to hydroxyl free radical generation $\mathrm{Fe}^{+2}$ reacts with $\mathrm{H}_{2} \mathrm{O}_{2}$ to form a hydroxyl radical. This radical binds to sugars, amino acids, phospholipids, DNA bases, and organic acids and once accumulated can lead to cell death [30]. Thus, this metal metabolism process is controlled by physiological and environmental conditions based on the metal concentration. It must be tightly regulated to avoid the formation of reactive oxygen species [31]. High concentrations of this metal lead to a shutdown of expression of many genes involved in iron uptake during iron limitation conditions [32].

Iron homeostasis in bacteria is finely controlled to mediate sufficient iron uptake but preventing toxicity resulting from excess iron enhancing reactive oxygen radical production. In many bacteria, a regulator (fur) of ferric acquisition senses Intracellular iron levels and acts as the controlling transcription factor for iron homeostasis. Excessive intracellular iron results in a Fur- $\mathrm{Fe}^{2+}$ complex forming to inhibit transcription of siderophore iron acquisition genes, and so represses excess iron entry into the cell [18].

Siderophores are a group of structurally diverse small molecules (typically 500- to 1,000-Da) containing metalchelating motifs that can be classified as: (i) hydroxamates, $\mathrm{C}[=\mathrm{O}] \mathrm{N}-[\mathrm{OH}]$, which chelate ferric iron via a carbonyl group with an adjacent nitrogen; (ii) catechols, that bind ferric iron via hydroxyl groups, each catecholate group providing two oxygen atoms for chelation with iron; (iii) carboxylates, where iron binding is via hydroxyl-carboxylate and carboxylates and (iv) mixed-type siderophores that have both catechol- and hydroxamate-binding moieties [33].

The use of xenosiderophores as an uptake system has also been reported in bacteria. By using this system, also known as siderophore piracy, the microorganisms use siderophore produced by other microbial species in a competitive environment [34, 35]. Siderophore piracy involving Streptomyces was reported by Galet et al. (2015) showing that Pseudomonas fluorescens strain BBc6R8 utilizes the ferrioxamines and ferricoelichelin produced by Streptomyces ambofaciens ATCC 23877 as xenosiderophores.

Several siderophore mechanisms for transport, storage, and uptake of iron have been reported and differ depending on the organism involved. Gram-positive and Gram-negative bacteria use different siderophore-mediated $\mathrm{Fe}$ transport mechanisms. Basically, Gram-negative bacteria require a multistep process for siderophore uptake that involves: 


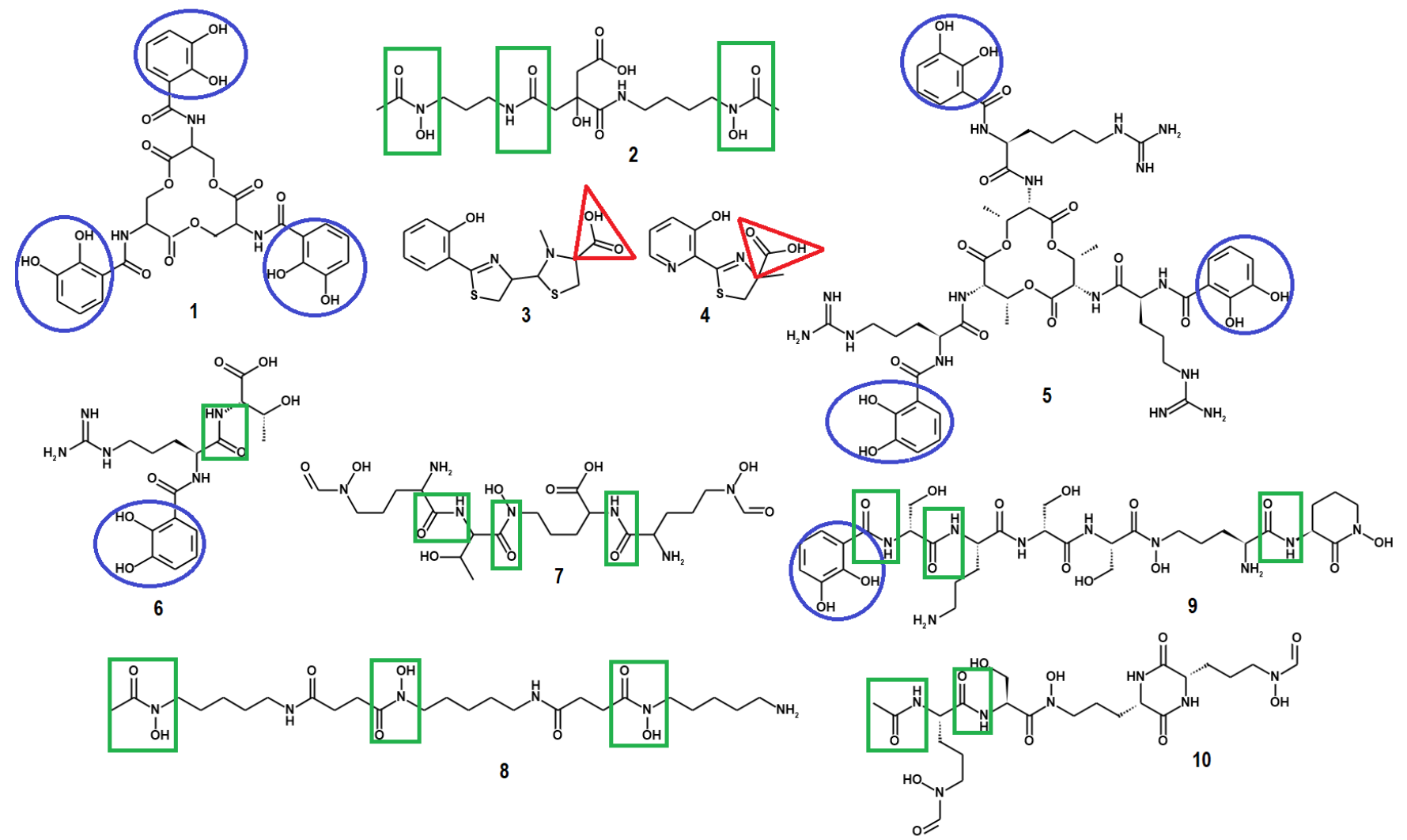

Figure 1: Examples of hydroxamate (green), catechols (blue), carboxylate (red) and mixed type siderophores produced by Streptomyces spp. 1- Enterobactin (S. tendae); 2- Fradiamine A - (S. fradie); 3- Pyochelin (S. scabies); 4- Ferrithiocin (S. antibioticus); 5- Streptobactin and 6- Benarthin (Streptomyces sp. YM5-799), 7- Coelichelin (S. coelicolor); 8- Desferrioxamine B (S. coelicolor and S. pilosus; 9Qinichelin (S. sp. MBT76) and 10- Foroxymithine (S. nitrosporeus).

a) a specific TonB-dependent outer membrane transporter that recognizes the $\mathrm{Fe}^{+3}$ - siderophore complexes at the cell surface, b) a periplasmic binding protein (PBP) that binds the ferric-siderophore in the periplasmic space, and c) and a $\mathrm{ABC}$ transporter to transfer the ferrous complex within the cytoplasmic membrane [36, 37].

Iron transport in Gram-positive bacteria involves lipoproteins, called siderophore-binding proteins or SBPs, which are anchored to the cell membrane. An SBP binds extracellular Fe-siderophores causing a conformational change in a SBP-permease complex that allows the transport of the ferric-siderophore complex across the membrane into the cytoplasm [38, 39].

\section{Streptomyces: A NATURAL SOURCE OF SIDEROPHORES AMONG BACTERIA}

Several reviews have highlighted the significance of Streptomyces secondary metabolite production and their biotechnology applications [40, 41, 42, 43]. However, less attention has been given to siderophore molecules produced by this genus. Identification of siderophores in Streptomyces from different sources and locations is an unexplored field that merits more attention. This section highlights valuable and interesting siderophores isolated from Streptomyces (Figure 1). The Siderophore Base is a Web Data Base of Microbial Siderophores available at http://bertrandsamuel.free.fr/siderophore_base/siderophores. php and allows the search for microbial siderophores and collates hundreds of known siderophore structures and the microorganisms that produce them. Some of the different types of siderophores produced by Streptomyces, and some other bacterial species are illustrated in Figure 1, labelled 1 to 10 .

Enterobactin (1), a tricatecholate siderophore was first isolated by bacteria of the family Enterobacteriaceae family, including Salmonella typhimurium and E. coli, and is one of the most studied siderophore systems. This molecule is also produced by Streptomyces tendae and Streptomyces sp. Tü 6125 [44].

Fradiamine A (2) and B are natural siderophores produced by the deep-sea Streptomyces fradiae MM456M and have shown moderate antibiotic activity against Clostridium difficile [45]. Other examples of siderophores isolated from marine environment are the catechol-type siderophore, streptobactin (5) and benarthin (6), isolated from Streptomyces sp. YM5-799 and the oxazole/thiazole derivatives, named tetroazolemycins A and B isolated from Streptomyces olivaceus FXJ8.012 [46, 47].

The siderophore pyochelin (3) is typically produced by members of the family Enterobacteriaceaea such as the opportunistic pathogen Pseudomonas aeruginosa and besides iron chelation and uptake roles, these molecules seem to be involved in infection and interactions with other biological ions [48]. The production of pyochelin by Streptomyces scabies 87-22 was also reported [49]. 
Table 1: Antimicrobial activity spectrum of the most known Sideromycins.

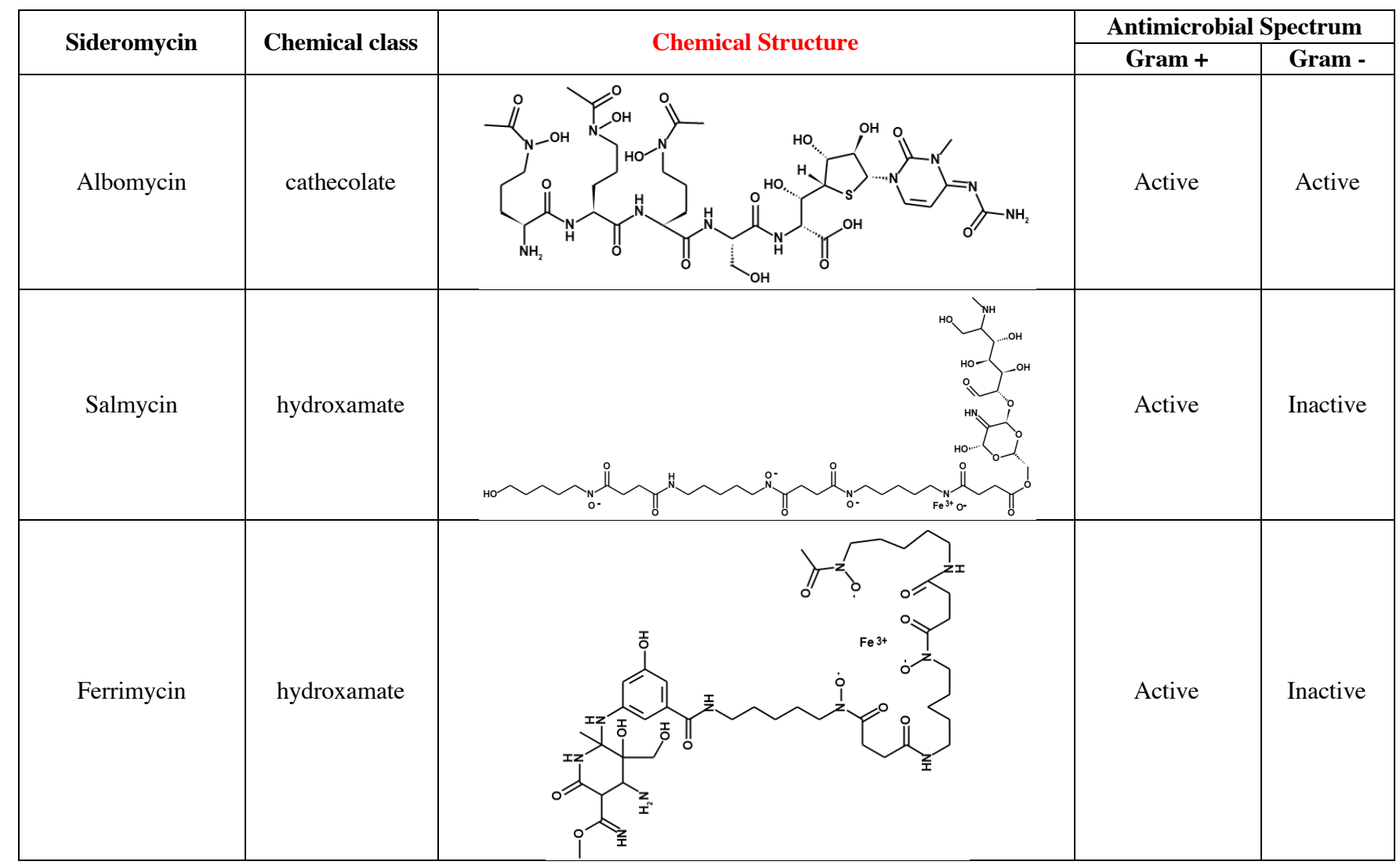

Desferrithiocin, also named ferrithiocin (4), is a thiazol siderophore isolated from Streptomyces antibioticus that exhibits anti-tumor cell proliferation activity and also has shown potential application in iron chelation therapy. This siderophore is an orally available iron chelator that is an attractive alternative for clinical treatment in iron overload disorders $[50,51]$.

Coelichelin (7) is a tris-hydroxamate siderophore from Streptomyces coelicolor and Streptomyces ambofaciens ATCC28377 [52]. S. coelicolor also produces Deferoxamines, also known as desferrioxamine B (8), that are siderophores with low-molecular-weights, produced and secreted by many actinomycetes, including species of Streptomyces, Nocardia and Micromonospora. These molecules are trihydroxamate-type siderophores synthesized by using the amino acids lysine and ornithine as precursors $[53,54]$.

Desferrioxamine (DFO, Desferal $\left.{ }^{\circledR}\right)$, a siderophore produced by Streptomyces pilosus, is a commercially available siderophore (Novartis Pharma AG, Basel, Switzerland). It has been used for the treatment of patients with iron and aluminum over-load and pathological iron deposition in humans such as occurs in hemochromatosis and $\beta$ thalassemia disease [55]. S. pilosus can produce and take up ferrioxamines B, D1, D2 and E, whereas $S$. viridosporus, $S$. lividans and S. olivaceus TÜ 2718 differentially produce and take up a range of ferrioxamines [55-58].

Desferrioxamine can be used to combat bacterial infection, but also has antiproliferative activity against leukemia and neuroblastoma cells in vitro and in vivo, anti-tumor activity, and can reduce inflammation and atherosclerotic lesions in animals [56-58].

Mixed type catecholate-hydroxamate siderophores named qinichelins (9) were identified in Streptomyces sp. MBT76, a prolific producer of antibiotics, such as isocoumarins, prodiginines, acetyltryptamine, and fervenulin [59]. This strain also produced C-Glycosylpyranonaphthoquinone molecules active against Gram-positive bacteria [60].

Another promising siderophore is foroxymithine (10), a trihidroxamate peptide and a potent chelator of the ferrous ion, produced by Streptomyces nitrosporeus and originally isolated as an inhibitor of angiotensin-converting enzyme; this siderophore also exhibits antineoplastic activity in combination with erbstatin $[61,62]$.

\section{POTENTIAL BIOTECHNOLOGICAL APPLICATIONS OF SIDEROMYCINS}

\subsection{Natural occurrence of sideromycins in Streptomyces}

Sideromycins are a class of antibiotics in which the bactericidal warhead is covalently linked to an antibiotic moiety attached to a siderophore (Figure 2). They represent an antibiotic delivery technology with untapped potential for

developing sophisticated microbe-selective antibacterial agents [63]. A search of the literature revealed that there are over 500 siderophores reported but many fewer syderomycins have been recently discovered. Examples of most known naturally occurring sideromycins in 
Streptomyces include albomycins, salmycins, ferrimycins, danomycins, and succinimycin (Table 1) [64-65].

Albomycins were among the first sideromycins to be characterized (e.g. Grisein [66]) and are produced by soil dwelling actinomycetes such as Streptomyces griseus ATCC 700974 [67]. They belong to the peptidyl nucleoside family and are the biosynthetic products of the conjugation of a thioribosyl nucleoside moiety linked to an iron-chelating siderophore mediated by an amide group [68].

Albomycins are broad-spectrum antibiotics highly effective against Gram-positive and Gram-negative bacteria such as the human pathogen Streptococcus pneumoniae causing pneumonia, meningitis, bacteremia, and otitis. Albomycin shows high antimicrobial activity with MICs as low as 10 $\mathrm{ng} / \mu \mathrm{L}$ and only $5 \mathrm{ng} / \mathrm{ml}$ against Escherichia coli, much lower than that of ampicillin $(100 \mathrm{ng} / \mathrm{ml})$ [63]. They can now be effectively synthesized and analogues tested against clinical pathogens such as Streptococcus pneumoniae and Staphylococcus aureus infections ) [69].

Salmycins are a class of naturally occurring "Trojan Horse" antibiotics produced by a particular strain of Streptomyces violaceus and consisting of a ferrioxamine $\mathrm{B}$ derivative, also called danoxamine and an aminodisaccharide (Figure 2). Salmycins A-D exhibit potent antibacterial activity against resistant Staphylococcal and Streptococcal strains and are used in clinical treatment of respiratory tract, urinary tract infections and other conditions [70]. However, salmycins do not show activity against Gram-negative bacteria [71].

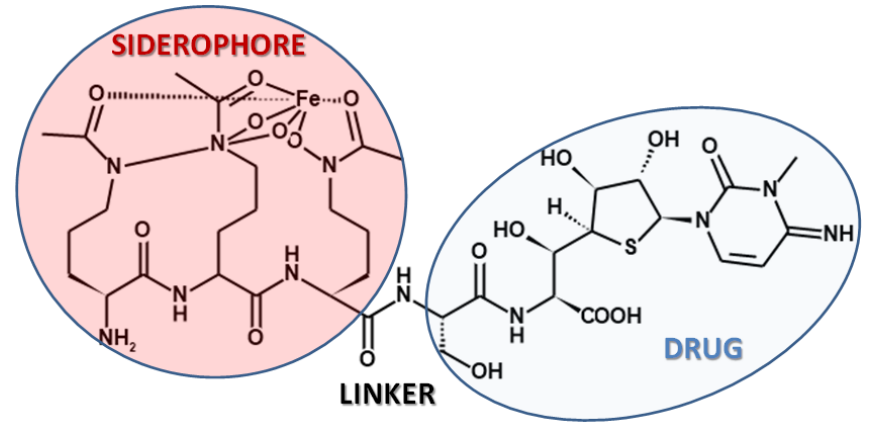

Figure 2: The chemical structure of a Siderophore-drug conjugate.

Ferrimycins, produced by S. griseoflavus (e.g. A1, A2, and B isolated from S. griseoflavus ETH 9578), are only active against Gram-positive bacteria $[64,72,73]$. When inactivated, the ferrimycins are transformed into compounds which possess the same properties as sideramines, the molecules that competitively antagonise the antibiotic effect of the sideromycins [74].

Another important member of the sideromycin class is Danomycin, a polypetide antibiotic con-taining iron, first identified in Streptomyces. albaduncus sp 13246. These molecules are closely related to the salmycins and are narrow-spectrum antibiotics, active against Gram-positive bacteria such as resistant Staphylococcus strains, but not against Gram-negative bacteria or fungi (Table 1) [75].

Succinimycin, is a sideromycin described by Haskell in 1963 and is produced by Streptomyces olivochromogenes. This molecule has activity against Gram-positive bacteria including staphylococci and streptococci strains and shows cross-resistance with grisein [76].

\subsection{Drug design of Sideromycins}

Taking these natural antibiotics as a model, many researchers began to develop a strategy in which natural siderophores or synthetic analogues are used for drug delivery [77]. This mechanism aims to accelerate the uptake of antibiotics by bacterial cells, especially in Gram-negative strains. These artificial conjugate siderophore-drugs greatly increase the effectiveness of known antibiotics and the concept is known as the Trojan Horse approach. Recent reviews emphasizing the importance of siderophores in the "Trojan Horse" approach have been published [78-82]. Negash et al. [83] have also emphasized the potential importance of this approach for treating multi-drug resistant Gram-negative pathogens recently.

Membranes are physical barriers protecting the cell and transmembrane uptake systems act as gates for many molecules., By using a nutrient delivery pathway, the outer membrane therefore no longer acts as a permeability barrier for the entry of antibiotics, and on the contrary, the rate of entry is increased, through active transport, beyond the diffusion rate $[82,84]$.

Natural siderophores or synthetic analogue examples include catecholate, hydroxamate, and carboxylate siderophores types; and glycopeptides, macrolides, fluroquinolones and $\beta$ lactams drugs. Siderophore-drug conjugates have three components systems consisting of a siderophore, linker, and the drug (Figure 2). The linker features are an essential component of the conjugate. The physical properties of linkers must be taken in consideration during the siderophore-drug conjugate design once it affects the efficiency of conjugation to antibiotics, and the drug release into the cell to give optimal affinity for the biological target [81-83, 85].

Most antibiotic conjugates designed to overcome antibiotic membrane permeability problems have used siderophores of either the catecholate- or hydroxamate-types (Table 2). These have been used as delivery vehicles aimed to target Gram-negative bacteria, especially $P$. aeruginosa, a pathogenic bacterium with a low permeability of the cell envelope causing natural resistance to many frontline antibiotics available for clinical treatment.

The design, synthesis, and characterization of synthetic sideromycins are reported in literature, and these include enterobactin-ampicillin and -amoxicillin conjugates. Under conditions of iron limitation, these siderophore-modified antibiotics provide enhanced antibacterial activity against uropathogenic E. coli CFT073 and UTI89, enterohemorrhagic $E$. coli $\mathrm{O} 157: \mathrm{H} 7$, and enterotoxigenic $E$. coli O78:H11, compared to the parent $\beta$-lactams [86].

$\mathrm{Ji}$ and Miller (2012) have designed a potential esterase triggered conjugate, desferrioxamine B-ciprofloxacin, and evaluated it for the ability to inhibit bacterial growth. The conjugate had the potential to use active iron transport processes to deliver the antibiotic to bacteria cells with

moderate to good antibacterial activities against $E$. coli and P. aeruginosa [87]. 
Table 2: Siderophore drug-conjugates and target bacteria.

\begin{tabular}{|c|c|c|c|c|}
\hline Siderophore & Antibiotic & Linker & Target bacteria & Ref \\
\hline $\begin{array}{l}\text { Catecholate-hydroxamate } \\
\text { mixed ligand }\end{array}$ & carbacephalosporin & succinyl & Acinetobacter baumannii & [54] \\
\hline Enterobactin & ampicillin/amoxicillin & polyethyleneglycol & E. coli & [86] \\
\hline DfoB* & ciprofloxacin & "trimethyl lock" & $\begin{array}{l}\text { Bacillus subtilis, } \text { S. aureus, } \\
\text { E. coli, } P \text {. aeruginosa }\end{array}$ & [87] \\
\hline Staphyloferrin A & fluoroquinolone & Amide linkage & $\begin{array}{c}\text { S.aureus, E. coli, } \\
\text { P.aeruginosa, Burkholderia cepacia, } \\
\text { Serratia marcescens }\end{array}$ & [90] \\
\hline Pyochelin analogue & oxazolidinone & succinic & P. aeruginosa & [91] \\
\hline $\begin{array}{l}\text { DfoB/ catecholate and } \\
\text { hydroxamate mixed } \\
\text { ligand }\end{array}$ & fluoroquinolone & $\begin{array}{l}\text { Quinone "trimethyl } \\
\text { lock"/succinic }\end{array}$ & $\begin{array}{l}\text { B. subtilis, S. aureus, } \\
\text { Micrococcus. luteus, E. coli, } \\
\text { P.aeruginosa, A. baumannii }\end{array}$ & [93] \\
\hline Hydroxamate & $\begin{array}{c}\beta \text {-lactams / } \\
\text { fluoroquinolone }\end{array}$ & succinoyl & S. aureus & [95] \\
\hline $\begin{array}{l}\text { Desferrioxamine B } \\
\text { (DfoB) }\end{array}$ & $\begin{array}{l}\text { loracarbef, } \\
\text { ciprofloxacin, and } \\
\text { nadifloxacin }\end{array}$ & maleimide & $\begin{array}{l}\text { B. subtilis, S. aureus, } \\
\text { M. luteus, P.aeruginosa }\end{array}$ & [96] \\
\hline $\begin{array}{c}\text { Synthetic fimsbactin A } \\
\text { analog }\end{array}$ & daptomycin & amide linkage & A. baumannii & [97] \\
\hline
\end{tabular}

Wittmann and coworkers have synthesized catecholates and mixed catecholate hydroxamate amino acids demonstrating high siderophore activity. These siderophore analogues were coupled with the $\beta$-lactam antibiotics ampicillin, amoxicillin, cephalexin or cefaclor. Both siderophore and siderophoredrug conjugates were tested for antibacterial activity and the siderophores alone were generally inactive while conjugates were highly active against the Gram-negative bacteria $P$. aeruginosa and Strenotrophomonas maltophilia but exhibited low activity against the Gram-positive strain $S$. aureus SG 511 [88].

Another study aimed to target pathogenic $P$. aeruginosa was performed by Hennard and coworkers in 2001 in which they synthesized four siderophore-based antibiotics formed by two quinolones - norfloxacin and benzonaphthyridone linked to the pyoverdin of $P$. aeruginosa ATCC 15692. Iron transport experiments showed that this conjugate promoted iron uptake in $P$. aeruginosa ATCC 15692 with a MIC lower than the MIC of free fluoroquinolone [89].

A series of conjugates was synthesized by Milner and coworkers using the carboxylate-type siderophore named Staphyloferrin A conjugated to a fluoroquinolone (ciprofloxacin and norfloxacin) antibiotic linked via amide bond formation. The conjugates were analyzed with a series of pathogenic bacteria with only some activity recorded against fluoroquinolone-susceptible strains but not ciprofloxacin- or norfloxacin-resistant bacteria [90]. These data indicated that the resistance mechanism already overcome this new molecule antimicrobial effect, needing further studies and different conjugates to explore better strategies to surpass this issue.

Paulen and coworkers reported the synthesis of conjugates of pyochelin with oxazolidinone antibiotics linked by succinate
[91] while Noël and coworkers conjugated functionalized Pyochelin with fluoroquinolones, including norfloxacin, ciprofloxacin and N-desmethyl-ofloxacin, which showed weak antibacterial activities against several $P$. aeruginosa strains [92].

A phase 3 clinical trial treating complicated human urinary tract infections with cefiderocol, the first siderophore antibiotic to reach late-stage development, has recently been reported (98). This synthetic compound has a siderophore catechol moiety attached to a cephalosporin molecule. Additionally, cefiderocol is stable against all classes of $\beta$ lactamases and the combination of efficient cell entry and stability to $\beta$-lactamase hydrolysis allows cefiderocol to overcome the three main mechanisms of antibiotic resistance used by Gram-negative bacteria against $\beta$-lactams: enzymatic hydrolysis, porin channel mutation, and efflux pump overproduction (99). The clinical trial indicated better clinical outcomes for cefiderocol treatments compared to treatments with Imipenem-cilastatin, the $\beta$-lactam based drug frequently used in these cases.

Another approach by Liu et al. [100] adopted a dual drug conjugate with a siderophore linked to a cephalosporin in turn attached to oxazolidinone. The cephalosporin is hydrolyzed by $\beta$-lactamase to release the oxazolidinone to inactivate Gram-negative targets. The authors described this process as induction of suicide in Gram-negative bacteria by a Gram-positive antibiotic.

Overall, these studies indicate that a Trojan horse delivery strategy should be explored further to target pathogenic bacteria, especially Gram-negative pathogens. Given the range of siderophores produced by Streptomyces, many new and effective siderophore-antibiotic conjugates could be designed and synthetized for treating infectious diseases 
caused by Gram-positive and Gram-negative bacteria (Table 2).

\section{Identification of siderophores by using genomic approaches: a feasible strategy}

Many bioactive molecules have been discovered and characterized by using genomic information together with in vitro and in vivo techniques such as metabolite purification, comparative genomic profiling, gene knockout and heterologous gene expression $[101,102]$.

The continual deposition of the complete genomes of microorganisms in databases and improvements in bioinformatic software contribute to the increase in the identification of potential new pathways for secondary metabolite biosynthesis. Several publications describing genomic sequences of Streptomyces species have been published due to their importance for the production of enzymes, antibiotics and other drugs and also for ecological and biodiversity studies [67]. Streptomyces is one of the most highly sequenced bacterial genera, with hundreds of draft genomes in the GenBank database [103].

Two bioinformatic strategies can be used to identify gene clusters related to biosynthetic pathways of siderophores as well as for other bioactive molecules: a) the search for conserved genes that are associated with the production of enzymes and secondary metabolites classes of antibiotics produced and $b$ ) the use of algorithms to associate the presence of clusters with specific Siderophores that are synthesized by members of the non-ribosomal peptide

synthetase (NRPS) family [104, 105]. This family presents an array of functional multi-domains and catalyzes partial

reactions of peptide synthesis [106]. NRPS are widely produced by bacteria, but mainly by the actinobacteria and filamentous fungi and are related to the production of various antibiotics such as penicillin, cephalosporin and vancomycin [107]. Siderophores generated by NRPS enzymes are primarily composed of amino acids, including nonproteinogenic amino acids, linked by peptide bonds. In contrast, hydroxamate and carboxylate siderophores are assembled mostly by NRPS-independent mechanisms [108]. Siderophore biosynthesis may also involve polyketide synthase (PKS) modules to include other functionalities into the backbone. These mechanisms are reported in the biosynthesis of some antibiotics such as erythromycin, rapamycin and rifamycin [109].

Many tools are available for in silico identification of NRPS and PKS gene clusters [110]. The antiSMASH program is a free online software used for the automated identification of gene clusters involved in biosynthesis of secondary metabolites in genomes of bacteria and fungi [111]. This tool is frequently used for genome mining in Streptomyces to identify clusters involved in the biosynthesis of polyketides, non-ribosomally synthesized peptide antibiotics, bacteriocins, and siderophores. It also allows the investigation of clusters whose products are unknown but possibly involved in the biosynthesis of a new secondary metabolite [112]. Methodologies involving gene cloning, heterologous expression, metabolite extraction, purification and chromatographic analyses are required for the identification of the final product [113].

The first example of a siderophore predicted through rational genome mining and later confirmed by gene knockout with comparative metabolic profiling was coelichelin, a siderophore encoded by the Streptomyces coelicolor genome. An NRPS system was also identified for assembly of this tetrapeptide iron chelator [114].

Nocardamin is a hydroxamate siderophore, first isolated from a Nocardia strain and later identified in other actinomycetes. The genome of Streptomyces avermitilis has a putative biosynthetic gene cluster for nocardamin and a desferrioxamine derivative [115]. S. avermitilis MA-4680 is well known for producing a variety of antibiotics such as the avermectins and oligomycin and its genome analysis led to the identification of 37 gene clusters involved in secondary

Table 3: Gene annotation of Streptomyces species whole genomes using the antiSMASH 4.0 platform database showing the highest similar biosynthetic cluster hits possibly encoding for siderophores compounds.

\begin{tabular}{|c|c|c|c|c|}
\hline Strain & $\begin{array}{c}\text { GenBank } \\
\text { accession number }\end{array}$ & From (bp) & To (bp) & $\begin{array}{c}\text { Siderophore } \\
\text { biosynthetic gene } \\
\text { clusters predicted } \\
\text { (\% similarity) }\end{array}$ \\
\hline S. avermitilis MA-4680 & NC_003155.5 & 6378181 & 6389953 & Grincamycin $(83 \%)$ \\
\hline S. lividans TK24 & NZ_CP009124.1 & 5290107 & 5301891 & Enduracidin $(83 \%)$ \\
\hline S. albus J1074 & NC_020990.1 & 4740450 & 4752270 & unknown \\
\hline S. griseus subsp.griseus NBRC 13350 & NC_010572.1 & 5573822 & 5585600 & unknown \\
\hline S. davawensis JCM 4913 & HE971709.1 & 6101969 & 6113741 & Grincamycin $(83 \%)$ \\
\hline S. laurentii ATCC 31255 & AP017424.1 & 2643751 & 2669872 & unknown \\
\hline S. rapamycinicus NRRL 5491 & CP006567.1 & 5052198 & 5063985 & unknown \\
\hline S. venezuelae ATCC 10712 & NC_018750.1 & 2794973 & 2806751 & unknown \\
\hline S. lydicus strain 103 & CP017157.1 & 2381075 & 2392883 & unknown \\
\hline S. bingchenggensisBCW-1 & NC_016582.1 & 7742586 & 7808875 & unknown \\
\hline S. griseochromognes ATCC 14511 & CP016279.1 & 9562300 & 9574069 & Marineosin $(83 \%)$ \\
\hline S. cyaneogriseus subsp. noncyanogenus NMWT & CP010849.1 & 2968691 & 2980460 & unknown \\
\hline S. coelicolor A3(2) & AL645882.2 & 3033895 & 3045682 & Enduracidin $(83 \%)$ \\
\hline
\end{tabular}


metabolite biosynthesis [116, 117].

Gubbens and coworkers reported three novel catecholatehydroxamate siderophores termed qinichelins in the antibiotic producing Streptomyces sp. MBT76. The elucidation of the chemical structure of these molecules encompassed bioinformatics, mass spectrometry, and NMR strategies. An in silico examination showed three gene clusters in the genome producing catecholate-peptide siderophores and another cluster producing a shared catecholate precursor. The authors also identified 55 putative biosynthetic gene clusters related to secondary metabolites by using the antiSMASH platform [59].

Park and coworkers have identified, by using a mass spectrometry together with a bioinformatic approach, a cyclic siderophore peptide from Streptomyces peucetius ATCC 27952 by studying functional cryptic genes and by analysis of the secretome, especially of NRP-type secondary metabolites [118]. This strain also produces anticancer anthracyclines and its genome contains an estimated 68 putative secondary metabolite gene clusters. [119].

Genome mining studies revealed that the plant pathogen Streptomyces scabies has several clusters encoding the production of siderophores. In this context, Kodani and coworkers (2013) isolated the siderophore scabichelin and also characterized the biosynthetic gene cluster that encodes the NRPS peptide [120].

Another study revealed that Streptomyces sp. ATCC 700974 and $S$. griseus strains, synthesize a catechol-peptide siderophore, namely griseobactin. The gene cluster for the biosynthesis of griseobactin was also described using bioinformatic tools. This is the first report identifying the gene cluster for the biosynthesis of 3,4-dihydroxybutyric acid and a catechol siderophore in Streptomyces [121].

In this perspective, a brief sequence analysis of several representative Streptomyces complete genomes available at GenBank was performed using the antiSMASH platform 4.0 revealing high similarity hits with biosynthetic gene clusters coding for siderophore compounds. Particularly, strains such as $S$. avermitilis MA-4680, $S$. lividans TK24 and $S$. griseochromognes ATCC 14511 contain gene clusters with high sequence similarity to gene clusters specifying synthesis of the siderophores such as Grincamycin (83\%); Enduracidin (83\%) and Marineosin (83\%) (Table 3). Meanwhile strains like $S$. laurentii ATCC 31255, $S$. bingchenggensis $\mathrm{BCW}-1$ and $S$. cyaneogriseus subsp. noncyanogenus NMWT have unknown biosynthetic gene clusters that potentially encode for a novel streptomycete siderophores (Table 3 ). These in silico results reinforced that bioinformatics approaches may help on the identification of the closest possible antimicrobial siderophore compounds produced by Streptomyces strains.

These data also illustrate the power of genome mining in discovering novel secondary metabolites that would be interesting to investigate in more detail. Genome mining, however, is dependent on algorithms such as antiSMASH identifying homology with existing known siderophore biosynthetic gene clusters. Any such prediction requires experimental validation by purifying the product of the cluster and proving its activity as an iron chelator. A limitation to this approach is that mining will be unlikely to predict a cluster that specifies a previously unknown molecular structure that may have iron-chelating siderophore activity. But, clearly, the accuracy of any predictive algorithm will improve as databases relating gene clusters to their products with known activities expand.

\section{CONCLUSION}

Bacterial antibiotic resistance represents a global issue to deal with as it is leading to a crisis in public health systems. Thus, new methodologies, strategies and bioactive compounds are urgently needed. Since iron uptake is essential for microbial survival, the targeting of siderophore biosynthesis pathways could be a strategy for new antimicrobial therapies. Moreover, siderophore-antibiotic conjugates represent an exciting way to repurpose old antibiotics and overcome uptake resistance mechanisms.

Siderophore biology is a growing and exciting field of research, with new siderophores constantly being discovered from Streptomyces and other bacteria. The use of genome mining represents an important tool for identification of new bioactive siderophores

\section{CONSENT TO PUBLISH}

Not applicable

\section{FUNDING}

This work was supported by CNPQ, FAPERJ and CAPES financially and with fellowships.

\section{CONFLICT OF INTEREST}

The authors confirm that this article content has no conflict of interest.

\section{ACKNOWLEDGEMENTS}

We gratefully thank PROPPi-UFF.

\section{REFERENCES}

[1] Kämpfer, P., 2012. Genus I. Streptomyces Waksman and Henrici 1943, 339AL emend. Witt and Stackebrandt 1990, 370 emend. Wellington, Stackebrandt, Sanders, Wolstrup and Jorgensen 1992, 159, in: Goodfellow, M., Kämpfer, P., Busse, H-J., Trujillo, M.E., Suzuki, K-I, Ludwig, W., Whitman, W.B. (Eds.), Bergey's manual of systematic bacteriology, Part B, vol. 5, 2nd edition. Springer, New York, pp. 1455-1767

[2] Barka, E.A.; Vatsa, P.; Sanchez, L.; Gaveau-Vaillant, N.; Jacquard, C.; Meier-Kolthoff, J.P.; Klenk, H.P.; Clément, C.; Ouhdouch, Y.; Van Wezel, G.P. Taxonomy, physiology, and natural products of Actinobacteria. Microbiol. Mol. Biol. Rev., 2016, 80(1), 1-43.

[3] Kinkel, L.L.; Schlatter, D.C.; Bakker, M.G.; Arenz, B.E. Streptomyces competition and co-evolution in relation to plant disease suppression. Res. Microbiol., 2012, 163(8), 490-499.

[4] Prakash, D.; Nawani, N.; Prakash, M.; Bodas, M.; Mandal, A.; Khetmalas, M.; Kapadnis, B. Actinomycetes: A Repertory of green catalysts with a potential revenue resource. Biomed. Res. Int., 2013, 2013, 1-8. 
[5] Lewis, K. Platforms for antibiotic discovery. Nat. Rev. Drug. Discov., 2013, 12(5), 371-387.

[6] Guimarães, D.O.; Momesso, L.S.; Pupo, M.T. Antibiotics: therapeutic importance and perspectives for the discovery and development of new agents. Quim. Nova, 2010, 33(3), 667-679.

[7] Chater, K.F. Recent advances in understanding Streptomyces. F1000Res., 2016, 5, 2795.

[8] Ventola C.L. The antibiotic resistance crisis part 1: Causes and treats. $P T, \mathbf{2 0 1 5}, 40(4), 277-283$.

[9] Labreche, M.J.; Lee, G.C.; Attridge, R.T.; Mortensen, E.M.; Koeller, J.; Du, L.C.; Nyren, N.R.; Treviño, L.B.; Treviño, S.B.; Peña, J.; Mann, M.W.; Muñoz, A.; Marcos, Y.; Rocha, G.; Koretsky, S.; Esparza, S.; Finnie, M.; Dallas, S.D.; Parchman, M.L.; Frei, C.R. Treatment failure and costs in patients with methicillin-resistant Staphylococcus aureus (MRSA) skin and soft tissue infections: A South Texas Ambulatory Research Network (STARNet) study. $J$. Am. Board. Fam. Med., 2013, 26(5), 508-517.

[10] Friedman, N.D.; Temkin, E.; Carmeli, Y. The negative impact of antibiotic resistance. Clin. Microbiol. Infect., 2016, 22(5), 416-422.

[11] Hiramatsu, K.; Katayama, Y.; Matsuo, M.; Sasaki, T.; Morimoto, Y.; Sekiguchi, A.; Baba, T. Multi-drugresistant Staphylococcus aureus and future chemotherapy. J. Infect. Chemother., 2014, 20(10), 593-601.

[12] Peleg, A.Y.; Hooper, D.C. Hospital-acquired infections due to Gram-negative bacteria. N. Engl. J. Med., 2010, 362(19), 1804-1813.

[13] Mehrad, B.; Clark, N.M.; Zhanel, G.G.; Lynch, J. Antimicrobial resistance in hospital-acquired Gramnegative bacterial infections. Chest, 2015, 147(15), 1413-1421.

[14] Santajit, S.; Indrawattana, N. Mechanisms of antimicrobial resistance in ESKAPE pathogens. Biomed. Res. Int., 2016, 1-8.

[15] Högberg, L.D.; Heddini, A.; Cars, O. The global need for effective antibiotics: challenges and recent advances. Trends. Pharmacol. Sci., 2010, 31(11), 509-515.

[16] Tacconelli, E.; Carrara, E.; Savoldi, A.; Harbarth, S.; Mendelson, M.; Monnet, D.L.; Pulcini, C.; Kahlmeter, G.; Kluytmans, J.; Carmeli, Y.; Ouellette, M.; Outterson, K.; Patel, J.; Cavaleri, M.; Cox, E.M.; Houchens, C.R.; Grayson, M.L.; Hansen, P.; Singh, N.; Theuretzbacher, U.; Magrini, N. WHO Pathogens Priority List Working Group. Discovery, research, and development of new antibiotics: The WHO priority list of antibiotic-resistant bacteria and tuberculosis. Lancet Infect. Dis., 2018, 18(3), 318327.

[17] Frieri, M.; Kumar, K.; Boutin, A. Antibiotic resistance. J. Infect. Public Health, 2017, 10(4), 369378.

[18] Ellermann, M.; Arthur, JC. Siderophore-mediated iron acquisition and modulation of host-bacterial interactions. Free Radic Biol Med. 2017 105, 68-78.

[19] . Golonka, R.; Yeoh, B.S.; Vijay-Kumar, M. The Iron Tug-of-War between Bacterial Siderophores and
Innate Immunity. J Innate Immun. 2019;11(3), 249262.

[20] Wright, G.D. Something old, something new: revisiting natural products in antibiotic drug discovery. Can. J. Microbiol., 2014, 60(3), 147-154.

[21] Khan, A.; Singh, P.; Srivastava, A. Synthesis, nature and utility of universal iron chelator - Siderophore: A review. Microbiol. Res., 2018 Jul - Aug; 212213:103-111.

[22] Ahmed, E.; Holmström, S.J. Siderophores in environmental research: roles and applications. Microb. Biotechnol., 2014, 7(3), 196-208.

[23] Hesse, E.; O'Brien, S.; Tromas, N.; Bayer, F.; Luján, A.M.; Van Veen, E.M.; Hodgson, D.J.; Buckling. A. Ecological selection of siderophore-producing microbial taxa in response to heavy metal contamination. Ecol. Lett., 2018, 21(1), 117-127.

[24] Johnstone, T.C.; Nolan, E.M. Beyond iron: Nonclassical biological functions of bacterial siderophores. Dalton. Trans., 2015, 44(14), 63206339.

[25] Morrissey, J.; Guerinot M.L. Iron uptake and transport in plants: The good, the bad, and the ionome. Chem. Rev., 2009, 109(10), 4553-4567.

[26] Lau, C.K.; Krewulak, K.D.; Vogel, H.J. Bacterial ferrous iron transport: The Feo system. FEMS Microbiol. Ver., 2016, 40(2), 273-298.

[27] Aguado-Santacruz, G.A.A.; Moreno-Gómez, B.A.; Jiménez-Francisco, B.B.; Gárcia-Moya, E.B.; Preciado-Ortiz, R.E. Impact of the microbial siderophores and phytosiderophores on the iron assimilation by plants: a synthesis. Rev. Fitotec. Mex., 2012, 35(1), 9-21.

[28] Oglesby-Sherrouse, A.G.; Djapgne, L.; Nguyen, A.T.; Vasil, A.I.; Vasil, M.L. The complex interplay of iron, biofilm formation, and mucoidy affecting antimicrobial resistance of Pseudomonas aeruginosa. Pathog. Dis., 2014, 70(3), 307-320.

[29] Saha, M.; Sarkar, S.; Sarkar, B.; Sharma, B.K.; Bhattacharjee, S.; Tribedi, P. Microbial siderophores and their potential applications: a review. Environ. Sci. Pollut. Res. Int., 2016, 23(5), 3984-3999.

[30] Touati, D. Iron and oxidative stress in bacteria. Arch. Biochem. Biophys., 2000, 373(1):1-6.

[31] Frawley, E.R.; Fang, F.C. The ins and outs of bacterial iron metabolism. Mol. Microbiol., 2014, 93(4), 609-616.

[32] Bogdan, A.R.; Miyazawa, M.; Hashimoto, K.; Tsuji, Y. Regulators of iron homeostasis: New players in metabolism, cell death, and disease. Trends Biochem. Sci., 2016, 41(3), 274-86.

[33] Zajdowicz, S.; Haller, J.C.; Krafft, A.E.; Hunsucker, S.W.; Mant, C.T.; Duncan, M.W.; Hodges, R.S.; Jones, D.N.; Holmes, R.K. Purification and structural characterization of siderophore (corynebactin) from Corynebacterium diphtheriae. PLoS One, 2012, 7(4):e34591.

[34] Galet, J.; Deveau, A.; Hôtel, L.; Frey-Klett, P.; Leblond, P.; Aigle, B. Pseudomonas fluorescens pirates both ferrioxamine and ferricoelichelin 
siderophores from Streptomyces ambofaciens. Appl. Environ. Microbiol., 2015, 81(9), 3132-3141.

[35] Traxler, M.F.; Seyedsayamdost, M.R.; Clardy, J.; Kolter, R. Interspecies modulation of bacterial development through iron competition and siderophore piracy. Mol. Microbiol., 2012, 86(3), 628-644.

[36] Krewulak, K.D.; Vogel, H.J. Structural biology of bacterial iron uptake. Biochim. Biophys. Acta, 2008, 1778(9), 1781-1804.

[37] Cornelis, P. Iron uptake and metabolism in Pseudomonads. Appl. Microbiol. Biotechnol., 2010, 86(6), 1637-1645.

[38] Fukushima, T.; Allred, B.E.; Sia, A.K.; Nichiporuk, R.; Andersen, U.N.; Raymond, K.N. Gram-positive siderophore-shuttle with iron-exchange from $\mathrm{Fe}$ siderophore to apo-siderophore by Bacillus cereus YxeB. Proc. Natl. Acad. Sci. U S A, 2013, 110(34), 13821-13826.

[39] Wilson, B.R.; Bogdan, A.R.; Miyazawa, M.; Hashimoto, K.; Tsuji, Y. Siderophores in iron metabolism: from mechanism to therapy potential. Trends. Mol. Med., 2016, 22(12), 1077-1090.

[40] Worrall, J.A.; Vijgenboom, E. Copper mining in Streptomyces: Enzymes, natural products and development. Nat. Prod. Rep., 2010, 27(5), 742-756.

[41] Barka, E.A.; Vatsa, P.; Sanchez, L.; Gaveau-Vaillant, N.; Jacquard, C.; Meier-Kolthoff, J.P.; Klenk, H.P.; Clément, C.; Ouhdouch, Y.; van Wezel, G.P.; Taxonomy, physiology, and natural products of Actinobacteria. Microbiol. Mol. Biol. Rev., 2015, 80(1), 1-43.

[42] Procópio, R.E.; Silva, I.R.; Martins, M.K.; Azevedo, J.L.; Araújo, J.M. Antibiotics produced by Streptomyces. Braz. J. Infect. Dis., 2012, 16(5), 466471.

[43] Hwang, K.S.; Kim, H.U.; Charusanti, P.; Palsson, B.; Lee, S.Y. Systems biology and biotechnology of Streptomyces species for the production of secondary metabolites. Biotechnol. Adv. 2014, 32(2), 255-268.

[44] Fiedler, HP.; Krastel, P.; Müller, J.; Gebhardt, K.; Zeeck, A. Enterobactin: The characteristic catecholate siderophore of Enterobacteriaceae is produced by Streptomyces species. FEMS Microbiol. Lett., 2001, 196(2), 147-151.

[45] Takehana, Y.; Umekita, M.; Hatano, M.; Kato, C.; Sawa, R.; Igarashi, M. Fradiamine A, a new siderophore from the deep-sea actinomycete Streptomyces fradiae MM456M-mF7. J. Antibiot., 2017, 70(5), 611-615.

[46] Matsuo, Y.; Kanoh, K.; Jang, J.H.; Adachi, K.; Matsuda, S.; Miki, O.; Kato, T.; Shizuri, Y. Streptobactin, a tricatechol-type siderophore from marine-derived Streptomyces sp. YM5-799. J. Nat. Prod., 2011, 74(11), 2371-2376.

[47] Liu, N.; Shang, F.; Xi, L.; Huang, Y. Tetroazolemycins A and B, two new oxazole-thiazole siderophores from deep-sea Streptomyces olivaceus FXJ8.012. Mar. Drugs, 2013, 11(5), 1524-1533.

[48] Brandel, J.; Humbert, N.; Elhabiri, M.; Schalk, I.J.; Mislin, G.L.; Albrecht-Gary, A.M. Pyochelin, a siderophore of Pseudomonas aeruginosa: physicochemical characterization of the iron(III), copper(II) and zinc(II) complexes. Dalton. Trans., 2012, 41(9), 2820-2834.

[49] Seipke, R.F.; Song, L.; Bicz, J.; Laskaris, P.; Yaxley, A.M.; Challis, G.L.; Loria, R. The plant pathogen Streptomyces scabies $87-22$ has a functional pyochelin biosynthetic pathway that is regulated by TetR- and AfsR-family proteins. Microbiology, 2011, 157(Pt9), 2681-2693.

[50] Anderegg, G.; Raber, M. Metal complex formation of a new siderophore desferrithiocin and of three related ligands. J. Chem. Soc. Chem. Commun., 1990, 17, 1194-1196.

[51] Kicic, A.; Chua, A.C.G.; Baker, E. Desferrithiocin is a more potent antineoplastic agent than desferrioxamine. Br. J. Pharmacol., 2002, 135(6), 1393-1402.

[52] Pohlmann, V.; Marahiel, M.A. D-Amino group hydroxylation of L-ornithine during coelichelin biosynthesis. Org. Biomol. Chem., 2008, 6, 18431848

[53] Chiani, M.; Akbarzadeh, A.; Farhangi, A.; Mazinani, M.; Saffari, Z.; Emadzadeh, K.; Mehrabi, M.R. Optimization of culture medium to increase the production of desferrioxamine B (Desferal) in Streptomyces pilosus. Pak. J. Biol. Sci., 2010, 13(11), 546-550.

[54] Wencewicz, T.A.; Miller, M.J. Biscatecholatemonohydroxamate mixed ligand siderophorecarbacephalosporin conjugates are selective sideromycin antibiotics that target Acinetobacter baumannii. J. Med.Chem., 2013, 56(10), 4044-4052.

[55] Mortazavi, M.; Akbarzadeh, A. Improvement of desferrioxamine B production of Streptomyces pilosus ATCC 19797 with use of protease inhibitor and minerals related to its activity. Indian J. Clin. Biochem., 2012, 27(3), 274-277.

[56] Meiwes, J.; Fiedler, H.P.; ZähneR, H.; KonetschnyRapp, S.; Jung, G. Production of desferrioxamine E and new analogues by directed fermentation and feeding fermentation. Appl. Microbiol. Biotechnol., 1990, 32(5), 505-510.

[57] Müller, G.; Raymond, K.N. Specificity and mechanism of ferriox-amine-mediated iron transport in Streptomyces pilosus. J. Bacteriol., 1984, 160(1), 304-312.

[58] Imbert, M., Béchet, M.; Blondeau, R. Comparison of the main siderophores produced by some species of Streptomyces. Curr. Microbiol., 1995, 31(2), 129133.

[59] Gubbens, J.; Wu, C.; Zhu, H.; Filippov, D.V.; Florea, B.I.; Rigali, S.; Overkleeft, H.S.; van Wezel, G.P. Intertwined precursor supply during biosynthesis of the catecholate-hydroxamate siderophores qinichelins in Streptomyces sp. MBT76. ACS Chem. Biol., 2017, 12(11), 756-2766.

[60] Wu, C.; Du, C.; Ichinose, K.; Choi, Y.H.; van Wezel, G.P. Discovery of C-Glycosylpyranonaphthoquinones in Streptomyces sp. MBT76 by a combined NMR- 
based metabolomics and bioinformatics workflow. $J$. Nat. Prod., 2017, 80(2), 269-277.

[61] Umezawa, H.; Aoyagi, T.; Ogawa, K.; Obata, T.; Iinuma, H.; Naganawa, H.; Hamada, M.; Takeuchi, T. Foroxymithine, a new inhibitor of angiotensinconverting enzyme, produced by actinomycetes. $J$. Antibiot., 1985, 38(12), 1813-1815.

[62] Imoto, M.; Umezawa, K.; Komuro, K.; Sawa, T.; Takeuchi, T.; Umezawa, H. Antitumor activity of erbstatin, a tyrosine protein kinase inhibitor. Jpn. J. Cancer Res., 1987, 78(4), 329-332.

[63] Braun, V.; Pramanik, A.; Gwinner, T.; Köberle, M.; Bohn, E. Sideromycins: Tools and antibiotics. Biometals, 2009, 22(1), 3-13.

[64] Hider, R.C.; Kong, X. Chemistry and biology of siderophores. Nat. Prod. Rep., 2010, 27(5), 637-657.

[65] Negash, K.H.; Norris, J.K.; Hodgkinson, J.T. Siderophore-Antibiotic Conjugate Design: New Drugs for Bad Bugs? Molecules 2019, 24(18), 33143330.

[66] Reynolds, D. M.; Schatz, A.; Waksman, S.A. Grisein, a new antibiotic produced by strain of Streptomyces griseus. Proc. Soc. Exp. Biol. Med, 1947, 64(1), 5054.

[67] Kulkarni, A.; Zeng, Y.; Zhou, W.; Van Lanen, S.; Zhang, W.; Chen, SA. Branch point of Streptomyces sulfur amino acid metabolism controls the production of albomycin. Appl. Environ. Microbiol., 2016, 82(2), 467-477.

[68] Zeng, Y.; Kulkarni, A.; Yang, Z.; Patil, P.B.; Zhou, W.; Chi, X.; Van Lanen, S.; Chen, S. Biosynthesis of albomycin $\delta 2$ provides a template for assembling siderophore and aminoacyl-tRNA synthetase inhibitor conjugates. ACS Chem. Biol., 2012, 7(9), 1565-1575.

[69] Lin, Z.; Xu, X.; Zhao, S.; Yang, X.; Guo, J.; Zhang, Q.; Jing, C.; Chen, S.; He, Y. Total synthesis and antimicrobial evaluation of natural albomycins against clinical pathogens. Nat. Commun. 2018, 9, 3445-3453.

[70] Vértesy, L.; Aretz, W.; Fehlhaber, H-W.; Koger, H. Salmycin A-D, Antibiotika aus Streptomycese violaceus, DSM 8286, mit siderophoreaminoglycosid-struktur. Helv. Chim. Acta., 1995, 78(1), 46-60.

[71] Wencewicz, T.A.; Möllmann, U.; Long, T.E.; Miller, M.J. Syntheses and biological studies of the naturally occurring salmycin "Trojan Horse" antibiotics and synthetic desferridanoxamine-antibiotic conjugates. Biometals, 2009, 22(4), 633-648.

[72] Urban, A.; Eckermann, S.; Fast, B.; Metzger, S.; Gehling, M.; Ziegelbauer, K.; Rübsamen-Waigmann, H.; Freiberg, C. Novel whole-cell antibiotic biosensors for compound discovery. Appl. Environ. Microbiol., 2007, 73(20), 6436-6443.

[73] Sackmann, W.; Preusser, P.; Neipp, L.; Kradolfer, F.; Gross, F. Ferrimycin A, a new iron containing antibiotic. Antibiotic Chemother., 1962, 12, 34-45.

[74] Bickel, H.; Gaeumann, E.; Keller-Schierlein, W.; Prelog, V.; Vischer, E.; Wettstein, A.; Zaehner, H. On iron-containing growth factors, sideramines, and their antagonists, the iron-containing antibiotics, sideromycins. Experientia, 1960, 16, 129-133.

[75] Tsukiura, H.; Okanishi, M.; Ohmori, T.; Koshiyama, H.; Miyaki, T.; Kitazima, H.; Kawaguchi, H. Danomycin, a new antibiotic. J. Antibiot., 1964, 17, 39-47.

[76] Haskell, T.H.; Bunge; R.H.; French; J.C.; Bartz; Q.R. Succinimycin, a new iron-containing antibiotic, $J$. Antibiot., 1963, 16, 67-75.

[77] Roosenberg, J.M.; Lin, Y.M.; Lu, Y.; Miller, M.J. Studies and syntheses of siderophores, microbial iron chelators, and analogs as potential drug delivery agents. Curr. Med. Chem., 2000, 7(2), 159-197.

[78] Page, M.G. Siderophore conjugates. Ann. N Y Acad. Sci., 2013, 1277, 115-126.

[79] Górska, A.; Sloderbach, A.; Marszałł, M.P. Siderophore-drug complexes: potential medicinal applications of the 'Trojan horse' strategy. Trends Pharmacol.Sci., 2014, 35(9), 442-449.

[80] Schalk, I.J.; Mislin, G.L.A. Bacterial iron uptake pathways: gates for the import of bactericide compounds. J. Med. Chem. 2017, 60(11), 4573-4576.

[81] de Carvalho, C.C.C.R.; Fernandes, P. Siderophores as "Trojan Horses": tackling multidrug resistance? Front. Microbiol., 2014, 5, article 290.

[82] Schalk, I.J. Siderophore-antibiotic conjugates: Exploiting iron uptake to deliver drugs into bacteria. Clin. Microbiol. Infect. 2018, 24, 801-802.

[83] Negash, K.H.; Norris, J.K.S.; Hodgkinson, J.T. Siderophore-antibiotic conjugate design: New drugs for bad bugs? Molecules 2019, 24, 3314-3330.

[84] Braun, V.; Braun, M. Active transport of iron and siderophore antibiotics. Curr. Opin. Microbiol., 2002, 5(2), 194-201.

[85] Pramanik, A.; Braun, V. Albomycin Uptake via a ferric hydroxamate transport system of Streptococcus pneumoniae. J. Bacteriol., 2006, 188(11), 3878-3886.

[86] Zheng, T.; Nolan, E.M. Enterobactin-mediated delivery of $\beta$-lactam antibiotics enhances antibacterial activity against pathogenic Escherichia coli. Am. Chem. Soc., 2014, 136(27), 9677-9691.

[87] Ji, C.; Miller, MJ. Chemical syntheses and in vitro antibacterial activity of two desferrioxamine Bciprofloxacin conjugates with potential esterase and phosphatase triggered drug release linkers. Bioorg. Med. Chem., 2012, 20(12), 3828-3836.

[88] Wittmann, S.; Schnabelrauch, M.; ScherlitzHofmann, I.; Möllmann, U.; Ankel-Fuchs, D.; Heinisch, L. New synthetic siderophores and their beta-lactam conjugates based on diamino acids and dipeptides. Bioorg. Med. Chem., 2002, 10(6), 16591670 .

[89] Hennard, C.; Truong, Q.C.; Desnottes, J-F.; Paris, JM.; Moreau, N.J.; Abdallah, M.A. Synthesis and activities of pyoverdin-quinolone adducts: a prospective approach to a specific therapy against Pseudomonas aeruginosa. J. Med. Chem., 2001, 44(13), 2139-2151.

[90] Milner, S.J.; Seve, A.; Snelling, A.M.; Thomas, G.H.; Kerr, K.G.; Routledge, A.; Duhme-Klair, A.K. Staphyloferrin A as siderophore-component in 
fluoroquinolone-based Trojan horse antibiotics. Org. Biomol. Chem., 2013, 11(21), 3461-3468.

[91] Paulen, A.; Hoegy, F.; Roche, B.; Schalk, I.J.; Mislin, G.L.A. Synthesis of conjugates between oxazolidinone antibiotics and a pyochelin analogue. Bioorg. Med. Chem. Lett., 2017, 27(21), 4867-4870.

[92] Noël, S.; Gasser, V.; Pesset, B.; Hoegy, F.; Rognan, D.; Schalk, I.J.; Mislin, G.L. Synthesis and biological properties of conjugates between fluoroquinolones and a N3"-functionalized pyochelin. Org. Biomol. Chem., 2011, 9(24), 8288-8300.

[93] Ji, C.; Mille, M.J. Siderophore-fluoroquinolone conjugates containing potential reduction-triggered linkers for drug release: Synthesis and antibacterial activity. Biometals, 2015, 28(3), 541-551.

[94] Rivault, F.; Liébert, C.; Burger, A.; Hoegy, F.; Abdallah, M.A.; Schalk, I.J.; Mislin, G.L. Synthesis of pyochelin-norfloxacin conjugates. Bioorg. Med. Chem. Lett., 2007, 17(3), 640-644.

[95] Wencewicz, T.A.; Long, T.E.; Möllmann, U.; Miller, M.J. Trihydroxamate siderophore-fluoroquinolone conjugates are selective sideromycin antibiotics that target Staphylococcus aureus. Bioconjug. Chem., 2013, 24(3), 473-486.

[96] Juárez-Hernández, R.E.; Miller, P.A.; Miller, M.J. Syntheses of siderophore-drug conjugates using a convergent thiol-maleimide system. ACS Med. Chem. Lett., 2012, 3(10), 799-803.

[97] Ghosh, M.; Miller, P.A.; Möllmann, U.; Claypool, W.D.; Schroeder, V.A.; Wolter, W.R.; Suckow, M.; Yu, H.; Li, S.; Huang, W.; Zajicek, J.; Miller, M.J. Targeted antibiotic delivery: Selective siderophore conjugation with daptomycin confers potent activity against multidrug resistant Acinetobacter baumannii both in vitro and in vivo. J. Med. Chem., 2017, 60(11), 4577-4583.

[98] Portsmouth, S.; van Veenhuyzen, D.; Echols, R.; Machida, M.; Ferreira, J.C.A.; Ariyasu, M.; Tenke, P.; Nagata, T.D. Cefiderocol versus imipenemcilastatin for the treatment of complicated urinary tract infections caused by Gram-negative uropathogens: A phase 2, randomised, double-blind, non-inferiority trial. Lancet Infect Dis., 2018, 12, 1319-1328.

[99] Tillotson, G,S. Trojan horse antibiotics-a novel way to circumvent Gram-negative bacterial resistance? Infect Dis. 2016, 9, 45-52.

[100] Liu, R.; Miller, P.A.; Vakulenko, S.B.; Stewart, N.K.; Boggess, W.C.; Miller, M.J. A synthetic dual drug sideromycin induces Gram-negative bacteria to commit suicide with a Gram-positive antibiotic. $J$. Med. Chem., 2018, 61, 3845-3854.

[101] Wackett, L.P. Genomics for natural product discovery. An annotated selection of World Wide Web sites relevant to the topics in microbial biotechnology. Microb. Biotechnol., 2016, 9(2), 275276.

[102] Niu, G. Genomics-driven natural product discovery in actinomycetes. Trends Biotechnol., 2018, 36(3), 238241 .
[103] Harrison, J.; Studholme, D.J. Recently published Streptomyces genome sequences. Microb Biotechnol., 2014, 7(5), 373-380.

[104] Weber, T.; Kim, H.U. The secondary metabolite bioinformatics portal: Computational tools to facilitate synthetic biology of secondary metabolite production. Synth. Syst. Biotechnol., 2016, I(2), 6979.

[105] Singh, M.; Chaudhary, S.; Sareen, D. Non-ribosomal peptide synthetases: Identifying the cryptic gene clusters and decoding the natural product. J. Biosci., 2017, 42(1), 175-187.

[106] Kadi, N.; Challis, G.L. Chapter 17. Siderophore biosynthesis a substrate specificity assay for nonribosomal peptide synthetase independent siderophore synthetases involving trapping of acyladenylate intermediates with hydroxylamine. Methods Enzymol., 2009, 458, 431-457.

[107] Crosa, J.H.; Walsh, C.T. Genetics and assembly line enzymology of siderophore biosynthesis in bacteria. Microbiol. Mol. Biol. Rev., 2002, 66(2), 223-249.

[108] Miethke, M.; Marahiel, M.A. Siderophore-based iron acquisition and pathogen control. Microbiol. Mol. Biol. Rev., 2007, 71(3), 413-451.

[109] Gomes, E.S.; Schuch, V.; de Macedo Lemos, E.G. Biotechnology of polyketides: New breath of life for the novel antibiotic genetic pathways discovery through metagenomics. Braz. J. Microbiol., 2014, 44(4), 1007-1034.

[110] Challis, G.L. Genome mining for novel natural product discovery. J. Med. Chem., 2008, 51(9), 26182628.

[111] Blin, K.; Wolf, T.; Chevrette, MG.; Lu, X.; Schwalen, CJ.; Kautsar, SA.; Suarez Duran, HG.; de Los Santos, ELC.; Kim, HU.; Nave, M.; Dickschat, JS.; Mitchell, DA.; Shelest, E.; Breitling, R.; Takano, E.; Lee, SY.; Weber, T.; Medema, MH. antiSMASH 4.0improvements in chemistry prediction and gene cluster boundary identification. Nucleic Acids Res., 2017, 45, W36-W41.

[112] Iftime, D.; Kulik, A.; Härtner, T.; Rohrer, S.; Niedermeyer, T.H.; Stegmann, E.; Weber, T.; Wohlleben, W. Identification and activation of novel biosynthetic gene clusters by genome mining in the kirromycin producer Streptomyces collinus Tü 365. J. Ind. Microbiol. Biotechnol., 2016, 43(2-3), 277-291.

[113] Xu, M.; Wang, Y.; Zhao, Z.; Gao, G.; Huang, S-X.; Kang, Q.; He, X.; Lin, S.; Pang, X.; Deng, Z.; Tao, M. Functional genome mining for metabolites encoded by large gene clusters through heterologous expression of a whole-genome bacterial artificial chromosome library in Streptomyces spp. Appl. Environ. Microbiol., 2016, 82(19), 5795-5805.

[114] Lautru, S.; Deeth, R.J.; Bailey, L.M.; Challis, G.L. Discovery of a new peptide natural product by Streptomyces coelicolor genome mining. Nat. Chem. Biol., 2005, 1(5), 265-269.

[115] Ikeda, H.; Kazuo, S.Y.; Omura, S. Genome mining of the Streptomyces avermitilis genome and development of genome-minimized hosts for 
heterologous expression of biosynthetic gene clusters. J. Ind. Microbiol. Biotechnol., 2014, 41(2), 233-250.

[116] Komatsu, M.; Komatsu, K.; Koiwai, H.; Yamada, Y.; Kozone, I.; Izumikawa, M.; Hashimoto, J.; Takagi, M.; Omura, S.; Shin-ya, K.; Cane, D.E.; Ikeda, H. Engineered Streptomyces avermitilis host for heterologous expression of biosynthetic gene cluster for secondary metabolites. ACS Synth. Biol., 2013, 2(7), 384-396.

[117] Nett, M.; Ikeda, H.; Moore, B.S. Genomic basis for natural product biosynthetic diversity in the actinomycetes. Nat. Prod. Rep., 2009, 26(11), 13621384.

[118] Park, H.M.; Kim, B.G.; Chang, D.; Malla, S.; Joo, H.S.; Kim, E.J.; Park, S.J.; Sohng, J.K.; Kim, P.I. Genome-based cryptic gene discovery and functional identification of NRPS siderophore peptide in
Streptomyces peucetius. Appl. Microbiol. Biotechnol., 2013, 97(3), 1213-1222.

[119] Dhakal, D.; Lim, S.K.; Kim, D.H.; Kim, B.G.; Yamaguchi, T.; Sohng, J.K. Complete genome sequence of Streptomyces peucetius ATCC 27952, the producer of anticancer anthracyclines and diverse secondary metabolites. J. Biotechnol., 2018, 267, 5054.

[120] Kodani, S.; Bicz, J.; Song, L.; Deeth, R.J.; OhnishiKameyama, M.; Yoshida, M.; Ochi, K.; Challis, G.L. Structure and biosynthesis of scabichelin, a novel trishydroxamate siderophore produced by the plant pathogen Streptomyces scabies 87.22. Org. Biomol. Chem., 2013, 11(28), 4686-4694.

[121] Patzer, S.I.; Braun, V. Gene cluster involved in the biosynthesis of griseobactin, a catechol-peptide siderophore of Streptomyces sp. ATCC 700974. J. Bacteriol., 2010, 192(2) 426-435. 